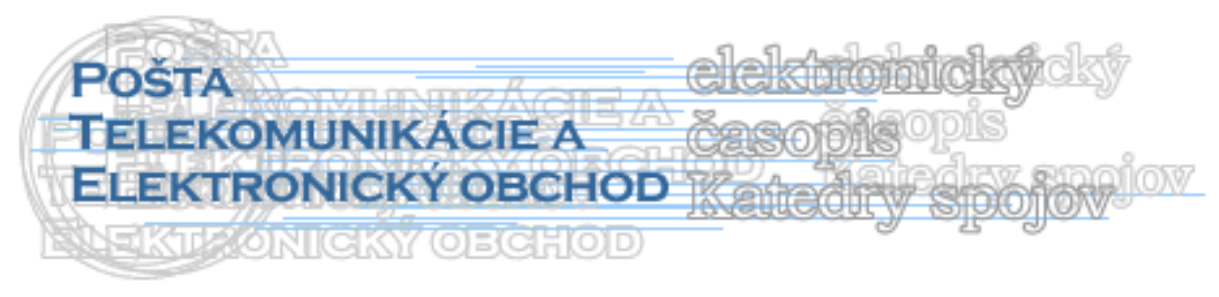

\title{
RFID IN POSTAL AND COURIER SERVICES
}

\author{
Libor Švadlenka ${ }^{1}$
}

\section{Introduction}

Radio frequency identification (RFID) is an increasingly mainstream technology, which mechanics are fairly simple: at various points along the supply chain, objects such as pallets, cases, carts and packages are detected by RFID readers. Mounted at a warehouse bay or truck entrance, or integrated with a portable handheld device, these readers detect an RFID tag mounted on the object and access the electronic product code (EPC) that has been programmed into the tag. In the future, this information will then be stored on an EPC global Network and accessed by eligible trading partners for use in supply chain management and other business applications. In this way, any object or container becomes intelligent and interactive, without the need for line-of-sight relationships, such as those required by bar codes.

The potential market for RFID in the postal and courier service is second only to that for the retail supply chain as shown below.

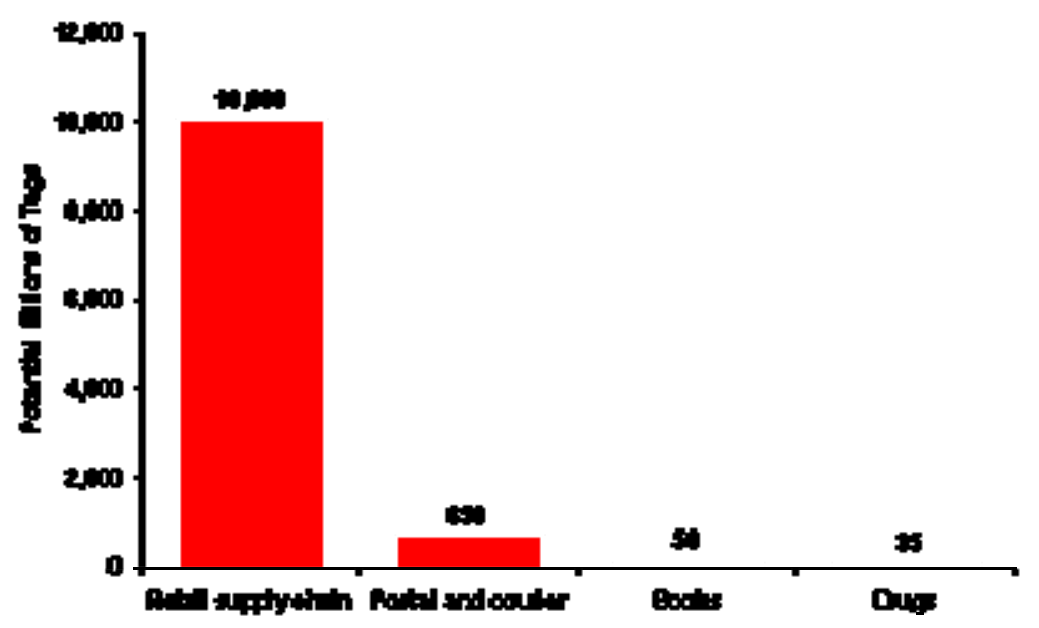

Figure 1 - Potential global market in billions of RFID tags

Source: IDTechEx

\section{Brief history and future}

The earliest development of an RFID-like technology was in the 1940s for aircraft recognition systems. Later, in the 1960s and 1970s, RFID was evolved for use in nuclear weapon and railroad car tracking systems. These areas had needs for tracking critical or expensive items that could tolerate the high costs of tags and readers available at the time. The first large-scale applications came in the 1980s for cattle identification, where tags were

\footnotetext{
${ }^{1}$ Ing. Libor Švadlenka, Ph.D., University of Pardubice, The Jan Perner Transport Fakulty, Department of Transport Management, Marketing and Logistics, Studentská 95, 53210 Pardubice, Czech Republic, tel.: +420466036375, fax: +420466036374, e-mail: Libor.Svadlenka@upce.cz
} 
actually imbedded under the animals' skin. Therefore, RFID is not a new technology; tagging has been around for more than half a century.

It is very likely that RFID will experience explosive growth in the next few years. This will be driven by adoption among prominent consumer products manufacturers and retailers as the next evolution beyond bar codes. For example the world's largest retailer - Wal-Mart, the world's fifth largest retailer - Metro, the largest retailer in the UK - Tesco and the US Department of Defense already announced they will require vendors to adopt RFID for some applications. These organizations will adopt a form of the EPC for their purposes although using different flavors of the EPC standard. For global development of this technology is evidently necessary to harmonize their various standards into one global standard, however this will take some time due to the origins of each organization.

However, the ultimate consequence of such a dramatic increase in RFID usage will be price reductions, and improvements in quality and features of tags. Other organizations can look forward to a much easier time with RFID as the groundswell builds around these early adopters.

\section{RFID opportunities}

The first opportunity from RFID is lowering the cost of information. Today, business information is often conveyed by a combination of bar codes and electronic data interchange (EDI) between computers. However, there are significant shortcomings:

- bar codes need to be physically oriented to be seen by a reader and must be read sequentially,

- bar codes cannot be changed once printed and are susceptible to dirt or scuffing,

- though the information connected with a bar code can be dynamic, transferring it to the point-of-need (typically the scan location) quickly and efficiently is highly uncertain.

In contrast, RFID tags do not need to be seen to be read, they can be read at a distance, even through or around many materials. Tags can electronically store large amounts of information, which can be changed and updated. And, since information is, by definition, attached to the thing itself, it's always available right at the point of use, without being separately transmitted. These features lower labor needed.

The second opportunity from RFID is increasing information accuracy. By allowing information to be captured and stored instantly, wherever it is most convenient, RFID helps ensure the information is correct. In fact, because RFID increases the instances in which humans can be taken out of the loop altogether, it can help raise accuracy levels to near perfection.

Finally, RFID tags can capture and convey new kinds of information that are difficult or impossible to get using traditional methods. Tags can be made unique and they can easily carry encrypted authentication information. RFID tags can also be combined with sensors on a chip, making it possible to have tags actually collect data about conditions they experience. 
Finished

goods inventory

visibility

Asset

visibility

Production

visibility

Safe and secure

supply chain

Supply chain planning
Better shipping and receiving produktivity

Increased order accuracy

Better returns processing

Improved raw materials receipts accuracy

Better work-in-process inventory management

Better receiving labor productivity

Better asset use through tracking of vehicles

Reusable containers

Visibility of other high-value assets

Improved recall management

Improved track and trace

Better expiration date management

Improvements in shrink

Reduction in inventory and working capital

Improved revenue through reduction in out-of-stocks ${ }^{\text {:ks }}$

Reduced expediting costs
$\%$ of respondents

Mean
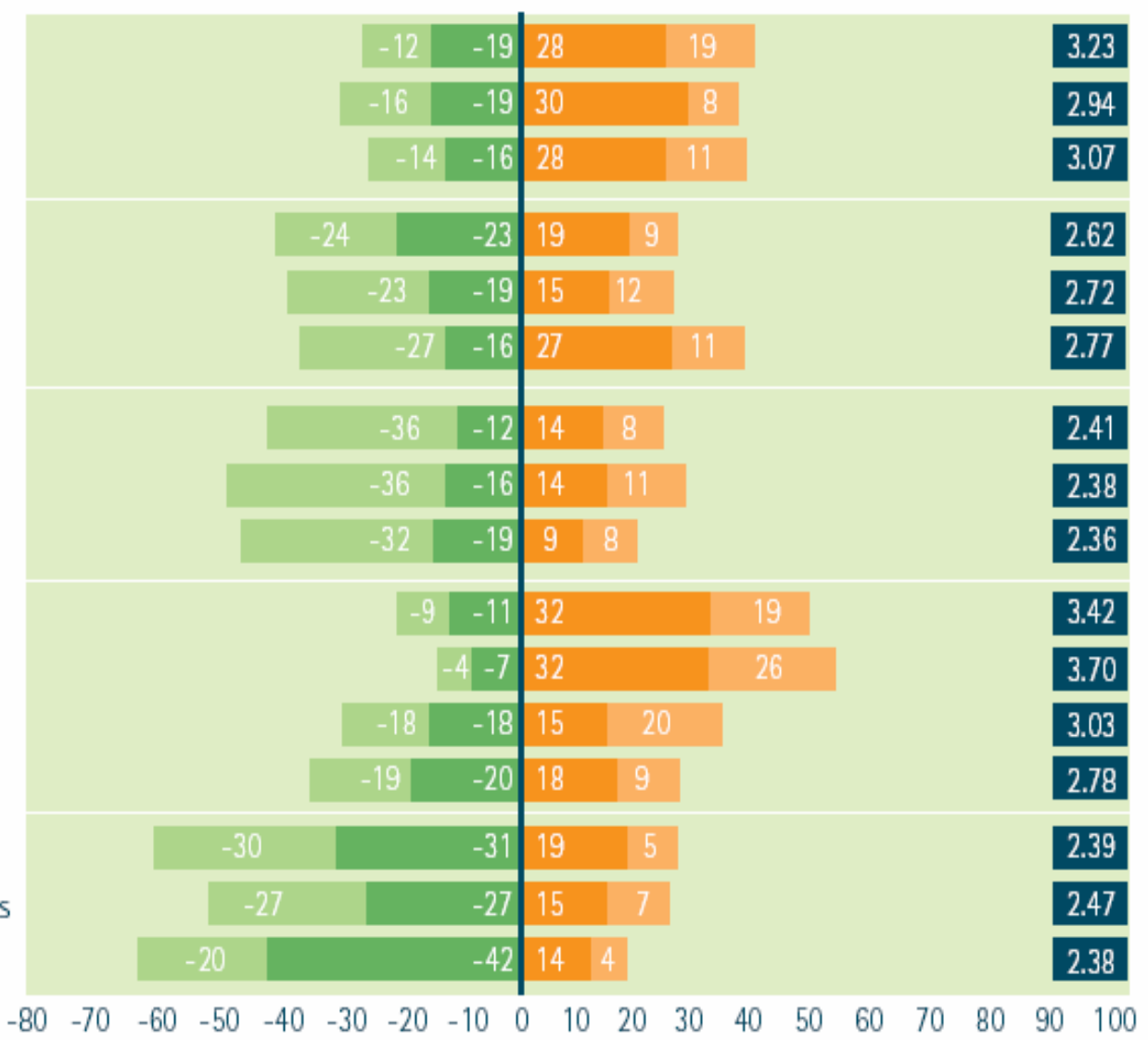

Not a benefit

\begin{tabular}{l|l|l|l}
1 & $2 \quad 3$
\end{tabular}

Strong benefit

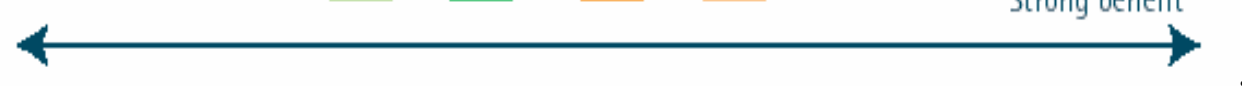

Source: Accenture survey

Figure 2 - Potential benefits of RFID 


\section{RFID threats}

While RFID offers undeniable benefits, there are several dangers for organizations that apply it. Perhaps the greatest concerns involve privacy. The idea that things might be uniquely identifiable and tracked by an invisible sea of radio waves makes many people nervous. Several recent efforts to apply RFID commercially on a large scale have been delayed until privacy concerns are addressed.

Standards are lacking for commercial applications. There are starting points for important applications, like the electronic product code (EPC) - analogous to the common universal product code - for marking consumer products. However, few standards exist for many important applications. Initial efforts by the Universal Postal Union have created standards for RFID information encoding.

RFID usage can put large demands on back-end computer systems. When an item is being read automatically over and over and generating hoards of data (compared to bar codes) each time, transaction volumes on supporting systems can grow enormously.

Early adopters will need to balance many complex trade-offs when choosing which RFID technologies to use. Radio-frequency bands, tag formats, data encoding schemes, reader technologies, the items to be tagged and the environments where they will be used all need to be considered during system design. The options are complex and subtle, meaning that expert advice is all but essential to arriving at the best solution.

Finally, the price of 20 to 50 cents of passive tags (designed to be written once and read many times) is still far too high for marking individual consumer products and the price of $\$ 10$ to $\$ 50$ of active tags is also far too high to allow the tag to be discarded after just one use.

\section{RFID in postal and courier services}

RFID is an idea whose time has come in postal, courier and high volume light logistics as shown on Figure 3.

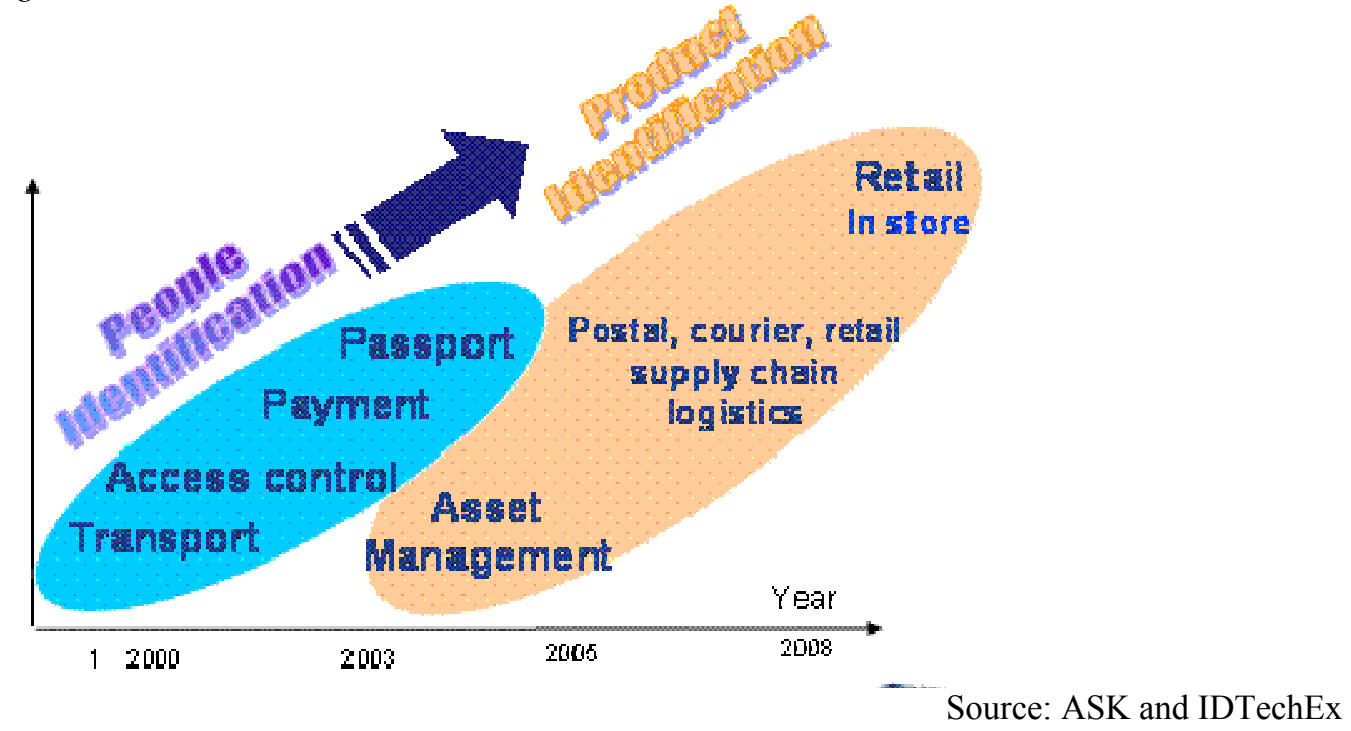

Figure 3 - Evolution of cost-effective applications of RFID. 
There are many reasons for this but the primary ones are that:

- Mandates from retailers are creating a yearly demand for billions of pallet/case RFID tags (ultimately about 40 billion yearly), reducing the cost of both RFID tags and systems of interest to postal and courier services for similar applications. Of the order of 500 million are being delivered on goods sent to retailers in 2006, this being four times the number of RFID tags delivered to all applications in the previous 60 years. Tag price of 5 cents is promised when billions are bought yearly in about two years.

- At the most used RFID frequency of $13.56 \mathrm{MHz}$, there is now booming usage in libraries, laundries, toys, tickets, cards and many other applications. This has led to value engineering, automation and volume production with prices of RFID tags and systems tumbling down and one billion RFID labels delivered in 60 years but the next billion RFID labels will be delivered under two years. Tag price reductions are in prospect here too. Indeed, this frequency is low enough for printed transistor circuits to be an option in 2007 and in mass use as labels by 2015. These replace the silicon chip, promising one cent price or less for complete RFID labels and eventually (after 2016?) direct printing onto items, just like barcodes today.

- Several companies (for example DAG Systems, SUBTROPIC) now offer or facilitate passive tags and systems that work at two to ten meters range and are usually more tolerant of water and metal than the old one. Using its new HF system based on new Schreiner RFID labels, it even reads metal cases at up to one meter when obscured by other metal cases. Only one year ago, those teaching RFID would say that HF tags, while being by far the most popular type, with over $55 \%$ of the market by value, could never work above one meter range and they only achieve one meter in a relatively unimpeded environment.

- For longer ranges (10 meters to two kilometers), tags with batteries are needed and here there is an advance from large devices with large batteries to ones with coin batteries and even many with printed batteries where the RFID tag takes the form of a label that may even act as a recorder of temperature, humidity etc at low cost. There are also new ways of locating things using beams with these active tags and ways of incorporating WiFi, ZigBee, Bluetooth, GPS or GSM for location and communication.

- Postal sorting machinery, fork lifts and other equipment is now increasingly available in RFID enabled form.

Today, postal operations have implemented RFID in various closed-loop systems to measure, monitor, and improve operations. For example, RFID is being used to monitor international mail service between major hubs. By randomly "seeding" tagged letters into trays, elapsed delivery time can be measured. This allows service issues to be identified and addressed in a reliable and cost-effective manner.

Other postal operations have piloted tracking mail containers to measure trailer utilization and to track container locations. Manual container tracking systems tend to break down when volumes are high and there's a deadline to meet departure times. By allowing information to be captured automatically, RFID makes sure it is done, even under stressful conditions. Postal managers can rely on the information to make decisions that improve transportation costs and to relocate containers when needed.

RFID-tracked mailbags, which provide delivery status, have already been created for priority mail services. Tagged mailbags are automatically read at specific points in the network to provide this automated track-and-trace capability.

Four additional areas can benefit from the cheap, accurate, and pervasive information obtained using RFID. Each of them has the prospect for returning substantial monetary benefits, as well as having the potential to significantly upgrade postal service capabilities, an ever more important consideration in the competitive delivery market. 


\subsection{Track and Trace}

Most postal services provide at least a limited form of track and trace, particularly for premium delivery services. Today, tracking uses bar codes. Switching to RFID tags can lower tracking labor by eliminating the need for most manual piece handling. It can also allow many more checkpoints to be conveniently captured within the postal network. Clearly such a pervasive use of tracking would increase the information volume handled by back-end systems.

\subsection{Workload and Transportation Planning}

Either in combination with pervasive mail piece tracking, or in conjunction with higher-level container tracking, it will be possible to capture much more reliable real-time information on workload volumes within the postal network. This kind of information is at the heart of efforts to make the mail sortation and transportation networks more dynamic. It will be much more practical to adjust routings to lower transport costs and speed mail efficiently through the network. The same information can also be used to bring about more efficient utilization of the postal labor force. By including both available and constrained capacities within the labor force, the flow of mail can be optimized.

\subsection{Asset Management}

RFID can also be used to track items other than mail: vehicles, trailers, rail cars, and various containers, for example. These are expensive assets representing an enormous capital investment within the network and their availability continually affects the capacity of the network. Pervasive, reliable tracking of these assets using RFID makes it practical to know where everything is and allows for better informed decisions to balance resources.

\subsection{Security}

The value of the previous opportunities varies with each operator's environment, but everyone shares the need to dramatically increase the security of mail movements. RFID can play a central role in helping provide higher levels of mail security. By enabling continuous monitoring of access and other factors, RFID can promote physical security, which is further enhanced using RFID's ability to provide authentication services for mail, and by capturing more refined information on mailers and recipients.

\section{Practical usage of RFID in postal and courier services}

\subsection{Deutsche Post/DHL Europe}

Deutsche Post (after DHL acquisition) ships about 27 billion items yearly, DHL being responsible for one billion yearly. DHL has carried out successful item level tagging using 13.56 MHz tags and wishes to tag everything in this way using EPC coding. In 2005 it has been assessing bids for a 1 billion requirement for HF tags and associated systems. Cost reduction and service improvement are the main objectives but crime reduction is also a possibility. Trevor Peirce from DHL, speaking at Smart Labels USA 2004, said they intend to roll-out using $13.56 \mathrm{MHz}$ which they are satisfied will be robust enough for their purposes.

6.2 UPS trucks

UPS is a follower in RFID. The company began a series of pilot tests in 2004 on both its package delivery business and its supply chain solutions business, which serve many customers who must comply with upcoming RFID mandates. In one trial passive RFID tags are replacing bar codes on reusable fibreboard tote boxes used to shuttle packages through UPS's automated facilities. The objective is to extend the life of the tote boxes and to reduce the read-failure rates of the barcodes, which tend to wear off over time. In another pilot, RFID tags have been attached to UPS trucks in an effort to monitor cost-effectively vehicle activity moving on and off the property at three different locations.

6.3 UPS tote boxes 
Much of the work to date has involved tinkering with the details of specific applications to achieve the right costs and performance trade-offs. For example, UPS has tried to balance the longevity of the tote box with the life of the tag, or to balance distance from the reader with the speed of the truck. Another challenge has been reducing the high rate of reader failures. UPS sees many opportunities to expand its use of RFID, particularly by starting to tag sensitive items. The handling of hazardous materials and high-value items, which currently require more human involvement are a priority here.

\subsection{Swedish Post}

Swedish Post has a parcel that detects and records tampering using RFID and other innovations abound, including RFID cards controlling driver access to postal vehicles and RFID enabled postal sorting equipment.

\subsection{Taiwan`s Chunghwa Post and Microsoft`s interest}

Very interesting is the fact that company as large as Microsoft has entered postal market due to RFID. The global potential is illustrated by its decision to offer its first postal systems in Taiwan and elsewhere in East Asia. Concretely in late 2005, Microsoft started marketing its new RFID system for postal and courier services at a stamp exhibition in Taiwan. It wishes to persuade the Taiwan government postal service with a device it claims can ensure the smooth, safe and recorded delivery of tagged packages and parcels. Taiwan's Chunghwa Post company, is now considering whether to use the Microsoft RFID package.

\section{Conclution}

RFID is a technology that has achieved its time. It's real, it works, and it's making never-before processes possible. Organizations that find ways to explore RFID, and at the same time create benefits, will be in the best position to leap ahead of their competitors as the systems mature and costs drop even further.

As I already said there is a great potential for RFID in the postal and courier service market because there are several possibilities to use it starting with track and trace to postal RFID system that completely automates the whole process of mail delivery from accepting the package to classification and dispatching.

Big especially international postal companies fully realize the significance of this technology and try apply it into their operation.

Although there are some difficulties restraining the development of this technology (especially the price of passive or active tags), it stands to reson that this problem will also be solved and this technology will replace current standard of automatic identification - bar codes with regard to evident benefits of RFID compared to bar codes.

\section{References}

[1] The role of RFID in supply chain planning. [online]. Accenture 2005. [cit. 2006-02-01]. available from WWW: <http://www.accenture.com/Global/Services/By_Subject/Supply Chain_Mgmt/default.htm>.

[2] $\bar{R}$ FID Applications for Postal Operations. [online]. Accenture 2004. [cit. 2006-02-01]. available from WWW: <http://www.postalproject.com/documents.asp?d_ID=2490>.

[3] RFID in the Postal Service. [online]. MoreRFID 2005. [cit. 2006-06-02]. available fromWWW: <http://www.morerfid.com/details.php?subdetail=Report\&action=details\& report id $=825 \&$ display $=$ RFID $>$.

[4] FABUŠ, J., GALOVIČ, M., KREMEŇOVÁ, I. RFID a ich použitie v rámci liberalizácie poštových trhov. In KREMEŇOVÁ, I. (ed.) POSTPOINT 2005 : 28. - 30. september 2005. FPEDAS University of Žilina. Žilina : University of Zilina, 2005. p. 83-87. ISBN 80-8070-454-6 